\title{
THE INCIDENCE OF CONGENITAL HEART DISEASE IN CHILDREN BORN IN GOTHENBURG 1941-1950
}

\author{
BY \\ LARS-ERIK CARLGREN \\ From the Department of Pediatrics, University of Gothenburg, Sweden \\ Received April 25, 1958
}

In spite of the great interest taken in cardiac malformations in recent years, few accurate figures are available, even in children, regarding their incidence and the life expectation in various types of lesion. Some studies of the frequency and significance of cardiac murmurs have been made in newborn infants, who have been followed up to the age of one or two years (Lyon et al., 1940; Taylor, 1953; Richards et al., 1955a; and Gyllenswärd, 1956) but the information gained in this way is not decisive since these early murmurs, even when persistent throughout infancy, do not always signify cardiac malformations and, vice versa, many cases of congenital heart disease are not diagnosed until later. Investigations in school children (Rauh, 1939; Robinson et al., 1948; and Stuckey et al., 1957) on the other hand, exclude the cases of cardiac malformation that have the worst prognosis and, consequently, die during infancy and early childhood. Most figures concerning the frequency of the individual lesions are obtained from necropsies (e.g. Abbot, 1936) or cardiac clinics (e.g. Wood, 1950; and Nadas, 1957) and are, therefore, not representative.

A determination of the over-all incidence of congenital heart disease and the relative frequency of the various types would require a field investigation within a given area with registration and examination of all known cases. To my knowledge only two investigations of this kind, both on children, have been made hitherto.

\section{Results OF EARLIER Studies}

In the first of these (Gardiner and Keith, 1951) the prevalence of heart disease (congenital and acquired) in Toronto children in the year 1948-49 was studied. Among a total of 74,450 children from 5 to 15 years of age the authors found 151 with congenital heart disease, all of whom were carefully examined by one of the authors-an incidence of $2 \cdot 1$ per thousand. There were 291 cases among the 134,367 children of all ages between 0 and 15 years $(2 \cdot 2$ per thousand). Ventricular septal defect was the most common individual lesion followed next by patent ductus arteriosus, tetralogy of Fallot, atrial septal defect, and isolated pulmonary stenosis. During the year 1948-49 there were 29 children who died from congenital heart disease, 24 of them during the first year of life. The most common causes of death were tetralogy of Fallot, transposition of the great vessels, anomalies of the aortic valve or ascending aorta, and ventricular septal defect. Because of the small proportion of infants in this series and the fact that most deaths occur in infancy, no accurate figures are available from this study about the mortality rates in the different lesions.

In the second study the problem was approached in a different way. MacMahon et al. (1953) collected the data of all known cases of congenital heart disease in children born in the years 1940-49 to mothers domiciled within the administrative boundary of Birmingham, using the records of all necropsies conducted in the various hospitals in the city, the clinical records of all patients by consultants and surgeons or under the supervision of school medical officers, and the local authority registers of infant deaths. There was a total of 199,418 births of which 5202 were stillbirths and 
194,216 live births. The incidence of congenital heart disease was 1.0 per thousand in the former, and 3.2 per thousand in the latter group. Two main sources of error were mentioned, namely (i) deaths wrongly attributed to congenital heart disease in cases without necropsy (mostly early domiciliary deaths) and (ii) the omission of patients who had not come to medical attention at the time of enquiry. With due allowance for these errors the authors concluded that the estimated incidence of 3.2 per thousand total births should only slightly understate the true incidence.

From their data, MacMahon et al. estimated the life expectation of children born with congenital heart disease. Of ten affected born alive, two would have died by the end of the first week, between three and four by the end of the first month, and six by the end of the first year. Only three to four would survive to the tenth birthday. As a consequence of this high mortality the incidence of congenital heart disease in children alive at ten years was estimated to be only $1 \cdot 1$ per thousand against 3.2 per thousand in infants alive at birth. This is far below the figures given by the Toronto group (2.1 per thousand) and by Stuckey et al. (2.8 per thousand) for school children 5-15 years.

Of the 633 total cases of congenital heart disease in the Birmingham series the diagnosis was not specified in $261(42 \%)$ : 145 of these had died and had not been submitted to necropsy or examined before death by a consultant, 10 were seen by the school medical officer only, and 106 had been examined by consultants (and not submitted to operation or necropsy) without any specified diagnosis being made. Of the 372 cases with a specified diagnosis 236 were examined post mortem, 19 were operated upon for persistent ductus, and 117 were seen by consultants (with full investigation including angiocardiography and cardiac catheterization in 28 cases and partial investigation in 89). The most common lesions were, in order, ventricular septal defect, persistent ductus arteriosus, transposition of great vessels, coarctation of the aorta, atrial septal defect, combined or not specified defects, tetralogy of Fallot, simple pulmonary stenosis, and persistent common truncus.

The investigations of Richards et al. (1955b) should be mentioned. As part of a comprehensive study of the relationship between infections and other complications of pregnancy and the outcome, they determined the frequency of congenital malformations of the heart in an unselected population of 6053 infants, who were followed from birth to the age of one year. Those in whom a congenital heart lesion was suspected, but not certain or not completely diagnosed, at the 1-year follow-up were examined by a cardiologist. The over-all incidence in this series was 8.3 per thousand births (54 per thousand stillbirths and 7.6 per thousand livebirths). These figures are far above those found by MacMahon et al. and would probably rise further if the children were followed up for longer. Possibly some of the surviving cases where a provisional diagnosis of septal defect was made ( 16 cases out of 20 ) will later prove not to have congenital heart disease since it is known that murmurs heard in infancy and thought to be organic may disappear later, but every case was very carefully examined. This is illustrated by the fact that the only cardiovascular malformation found in 6 of the 20 autopsies was an abnormal origin of the right subclavian artery or absence of the right hypogastric artery, anomalies that might have escaped notice at a routine necropsy. When these slight malformations are omitted the death rate from congenital heart disease in this series is 2.5 per thousand livebirths, which agrees well with the $2 \cdot 3$ per thousand found by MacMahon et al. As regards frequency of the separate lesions there were as many as 8 cases of tetralogy of Fallot among the 43 born alive with cardiac malformation, which is a far greater percentage than that found by others. Of interest in this connection is the suggestion of the authors of a possible relationship between the herpes simplex infection in the first trimester of pregnancy and tetralogy of Fallot in the child.

\section{Results at GothenburG}

The city of Gothenburg ( $c a .393,000$ inhabitants in 1957) seems to be well suited for a study of this subject. A cardiac clinic was opened at the Children's Hospital in 1951 and from the outset has been conducted by the author. All cases of certain or suspected heart disease known to the school health officers, the physicians in charge of the child health centres, and the general practitioners 
of the city have been referred to the clinic, where the author has personally examined all of them. Practically all births take place in the two maternity hospitals, where all newborn infants are examined by pædiatricians on at least two occasions, at birth and before discharge. Finally, autopsy is very seldom refused and has been performed in a large percentage of the deaths.

The study, which was begun in 1951, covers all known cases of congenital heart disease among infants born in 1941-50 to mothers domiciled in the city of Gothenburg. Practically all the children with cardiac murmurs registered in the newborn period, who have not otherwise (see above) come into contact with the cardiac clinic, have been traced and when desirable examined by the author. A few children who have moved to another area have been seen by other physicians and their findings evaluated. In those children who died without having necropsy (none of them was seen by the author) the validity of the clinical diagnosis was judged from all available data.

Incidence. The incidence of congenital heart disease in stillborn infants could not be established with certainty, since autopsy records are lacking in many stillbirths during the earlier years under

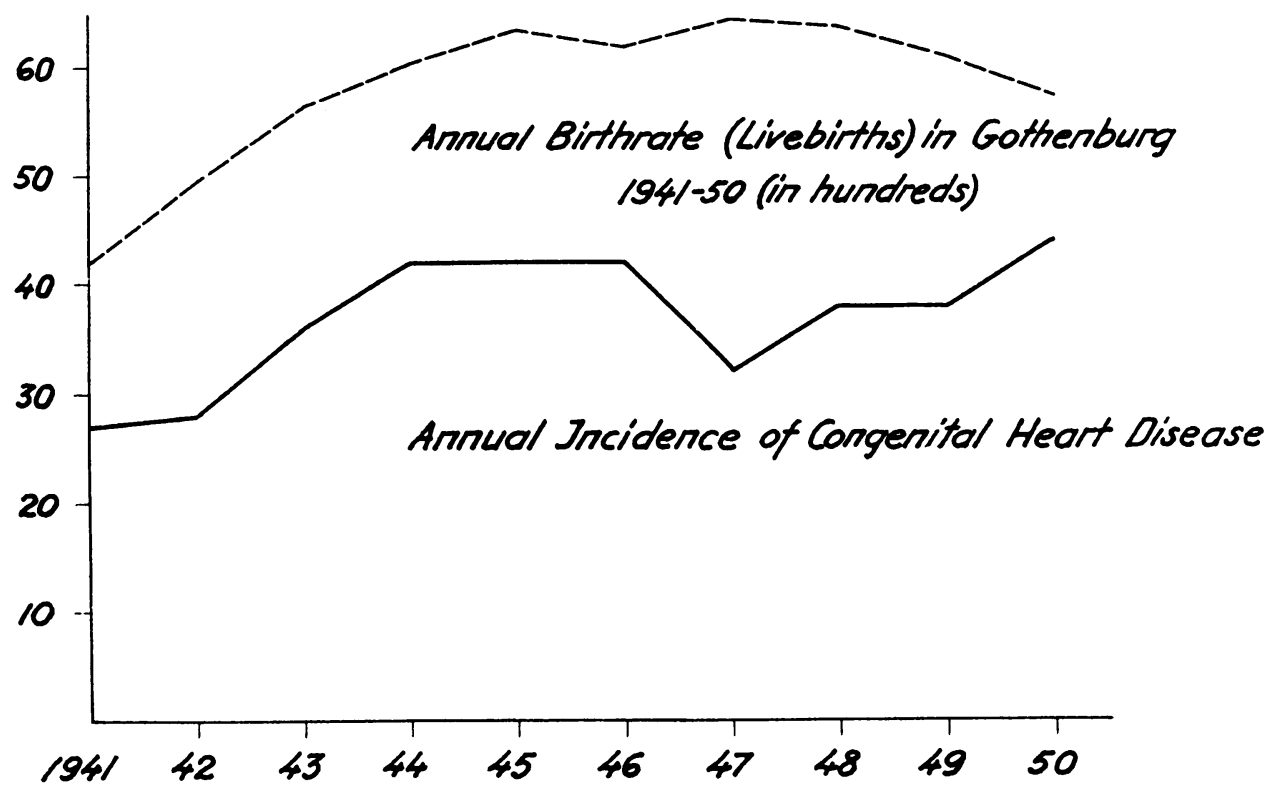

Fig. 1.-Annual incidence of congenital heart disease compared with annual birth-rate (live births) during the period under investigation. There were 369 cases among 58,105 live births (0.64\%).

investigation. Among 408 stillborn babies, cardiac malformations were found in three cases (persistent common truncus in two and transposition of great vessels in one). This number is too small to have any statistical value and this is true of the series of Richards et al. also (6 cases among 111 stillbirths $>500$ g.). In contrast, MacMahon et al. found only 5 cases among 5202 stillbirths, which is a remarkably low figure: it is hard to understand why the incidence should be lower in stillborn than in liveborn infants.

There were 369 cases of congenital heart disease in a total of 58,105 livebirths taking place during the period of investigation-an over-all incidence of 6.4 per thousand (Fig. 1), which is double that found by MacMahon et al. (3.2 per thousand). The difference may be real but is more likely due to omission of several mild cases in the Birmingham investigation, partly because of the shorter period of follow-up (3-11 years against 7-16 in the present study). This view is supported by the fact that the mortality rate from congenital heart disease, when given as a percentage of liveborn children, was about the same in the Birmingham series and in the present one $(2.3$ and 2.5 per thousand, respectively). Another explanation would be, of course, that congenital heart disease has been 
diagnosed too readily by us. It is true that most of the surviving cases have not been submitted to heart catheterization or angiocardiography (appendix), but the clinical signs supported by electrocardiogram, phonocardiogram, X-ray, and electrokymogram have been highly suggestive in all of them.

Sex Ratio. Of the 369 cases, 204 (55\%) were boys and $165(45 \%)$ girls. In the Toronto series the corresponding figures were 51 and 49 per cent, and in the Birmingham cases 53 and 47 per cent, respectively.

Familial Incidence and Heredity. The present material is not well suited for a study of the familial incidence of congenital heart disease, owing to the small number of cases. An estimation of the risk of having more than one affected child in a family should be based on the number of later-born siblings which, however, has not been brought up to date in most cases. In this series, only 104 siblings are known to have been born after the affected children in 81 families, and two of them had congenital heart disease. Both these children had proven pulmonary stenosis. McKeown et al. (1953) found six cases of cardiac malformation in 342 later-born siblings of 417 affected children, which was about six times the expected incidence of 3.2 per thousand.

In 3 instances out of 286 families where the history was taken, one parent was known to have a congenital heart lesion. Although the number is too small for statistical conclusions it is perhaps noteworthy that of these three pairs aortic stenosis was present in son and father in two, and atrial septal defect in daughter and father in the third. It is at least tempting to think of a hereditary factor working here. In two instances the affected child, in each case with the tetralogy of Fallot, was a homozygous twin: in both, the other twin was normal.

Pregnancy and Virus Infections. In 269 cases the mother was asked about rubella or other virus diseases during early pregnancy. A positive reply was obtained in seven cases only (rubella in five, and measles and mumps in one case each). This figure is not reliable since the investigation was retrospective on this point and the incidence of rubella in mothers giving birth to normal children was not known. It conforms, however, not only with other retrospective studies but also with the prospective investigation by Richards et al. (1955) who were unable to find any close relationship between congenital heart lesions and infections during early pregnancy; however, only four cases of rubella were encountered in their series of 5964 pregnancies. Lundström (1958) on the other hand, has noted 12 proven cases and a further 18 with probable congenital heart disease among the children of 600 women who contracted rubella in the first four months of pregnancy during an epidemic in Sweden in 1951, making an incidence of 2 to 5 per cent. The incidence of cardiac malformations in an equal number of controls has been 0.5 to 1 per cent, the difference being statistically significant.

The finding of a persistent ductus arteriosus in 6 of the 7 cases in the present series where the mother had virus disease is impressive, since the total number with a persistent ductus where a history of pregnancy was taken was only 28. Apparently, maternal virus disease may be a causative factor at least in this single malformation. This agrees with some other reports in which persistent ductus has been found to be the most common lesion caused by maternal rubella (Gibson and Lewis, 1952, and Stuckey, 1956).

If virus disease were an important causative factor in congenital heart disease, one would expect to find a seasonal variation in the numbers born with heart lesions, since rubella and measles and mumps have their peak of incidence in late winter and early spring. However, in the present series the months of birth are fairly evenly distributed over the year and periods of widespread epidemics of measles and mumps (rubella not being notifiable) have not been followed by a corresponding increased frequency of congenital heart disease. Rutstein et al. (1952) found a seasonal incidence in their 254 cases of persistent ductus (with a peak in October to January) which roughly corresponded with that of rubella notification in Massachusetts seven months earlier. Record et al. (1953) in a series of 166 persistent ductus cases noticed a seasonal fluctuation only in girls, but were unable to show any relationship between this fluctuation and the seasonal incidence of rubella. In the prospective investigation of Richards et al. (1955) no seasonal concentration of conceptions 
was revealed, but the numbers in their series were rather small. In the present study there seems to be a fairly good correlation between the number of infants with congenital heart lesion born every year, and the total number of livebirths (see Fig. 1).

\section{Mortality}

Most deaths occurred during the first month of life (81 cases), 52 of these dying in the first week: 32 died during the next five months. A further 12 died before the age of one year, 9 in the second and third years, 6 between the ages of three and six years, and 5 between seven and fourteen years. The cumulative mortality is shown in Fig. 2.

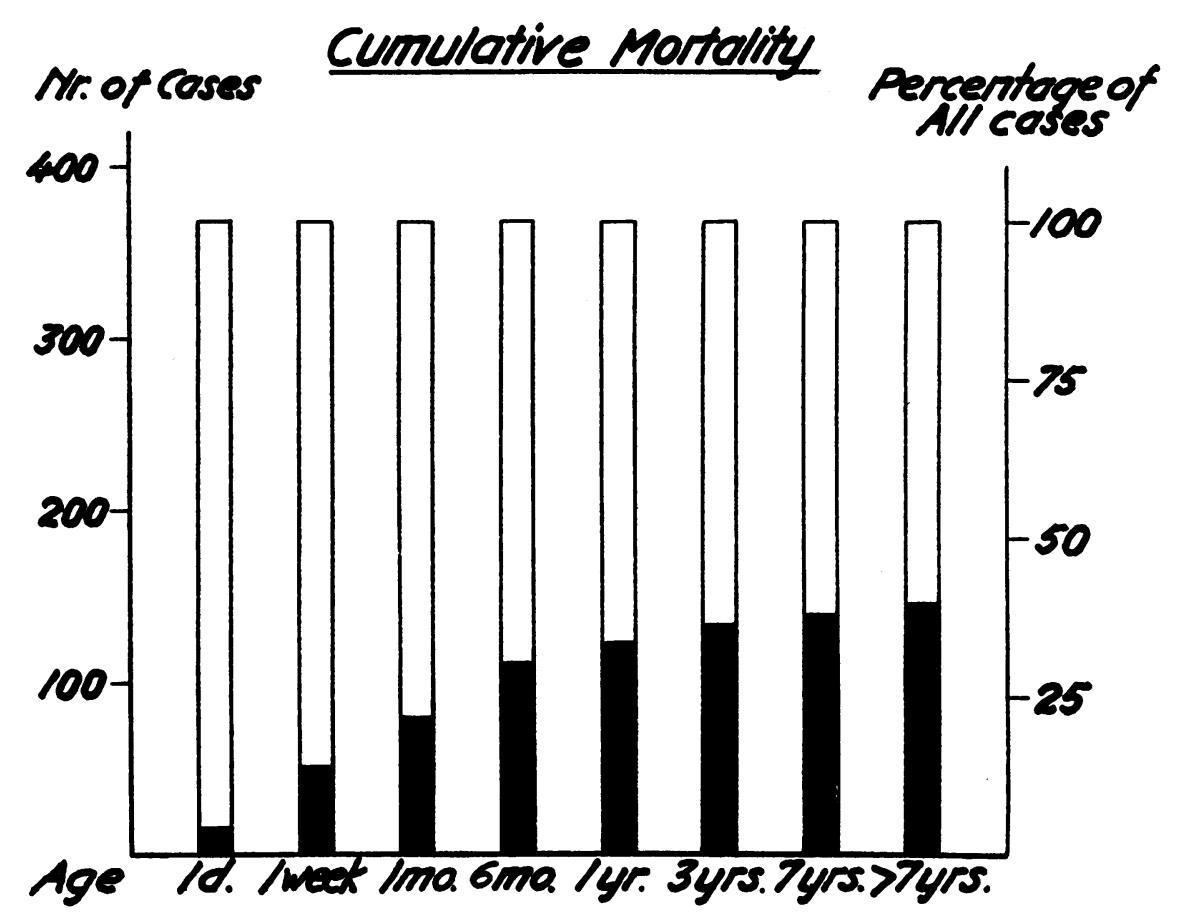

Fig. 2.-Cumulative mortality rate by the end of different age periods.

This age distribution of deaths is in good conformity with the figures given by MacMahon et al., and the total mortality, 145 deaths out of 58,105 live births ( 2.5 per thousand) is of the same order as in their series. The follow-up time in the present study exceeds theirs by about five years, but this is not of much importance since more than 90 per cent of all deaths occurred before the age of three years.

In 79 , or slightly more than half the cases, other causes contributed to the fatal outcome. They were at least partly responsible in two-thirds of the 81 deaths in the first month: birth trauma and/ or asphyxia in 19 cases $(23 \%)$, lower respiratory disease or other severe infection in $22(25 \%)$, associated gross malformation outside the heart in 5, and a birth weight less than $2000 \mathrm{~g}$. in 8 . Of the 44 deaths during the rest of the first year, signs of severe, lower respiratory infection were present in $17(21 \%)$.

There were 34 mongols in the total series, 19 of whom died. Other associated malformations were present in 29 cases, with 23 deaths. Obviously, congenital heart disease when combined with other deformities has a higher mortality (about two-thirds in this series) than if it occurs as a single lesion (about two-fifths). 
The percentage with associated malformations other than mongolism (14 out of 43 live births) was far greater in the series of Richards et al. than in the present one, probably because malformations were more thoroughly searched for, owing to the prospective nature of this investigation, and also in the series of MacMahon et al. $(21 \%)$, perhaps because they included a smaller proportion of mild cases.

224 cases $(61 \%)$ are still alive, the period of follow-up varying between 7 and 16 years. This percentage is far above that given by MacMahon et al., according to whom only between 30 and 40 per cent would be expected to survive ten years. A possible explanation (the omission of several mild cases) has already been discussed.

\section{RELATIVE INCIDENCE OF THE INDIVIDUAL LESIONS}

The accuracy with which a specific diagnosis of cardiac malformations can be made depends, of course, on the diagnostic methods used. Autopsy has been performed in all but 17 of the 145 deaths in the present series. Three of the exceptions were "blue babies" and six were mongols who probably had a common atrio-ventricular canal or some other kind of septal defect. The diagnoses are listed in Appendix A.

The method of diagnosis used in the 224 surviving children is shown in Appendix B. Full investigation, including heart catheterization, selective angiocardiography, and/or operation has been carried out in 103 cases. Only clinical examination with some of the tests mentioned was performed in the remaining 121 cases.

The diagnosis should be reasonably reliable even without special investigations in cases of persistent ductus, of moderate or severe aortic or pulmonary stenosis, and of atrial septal defect. The typical murmur in ventricular septal defect should also enable a positive diagnosis in most cases. A group of cases remains, however, in which no specified diagnosis has as yet been reached (30 cases). This includes thirteen mongols in whom an accurate diagnosis has not been called for, three other children with loud systolic murmurs who have not been seen by the author, and five others with harsh, basal systolic murmurs where it has not been possible to differentiate clinically between valvular (or infundibular) stenosis or septal defect and investigation has been refused. Finally, there are nine cases that may be examples of mild pulmonary valvular stenosis or idiopathic pulmonary dilatation or small atrial septal defects, where we have refrained from investigation owing to the complete absence of symptoms. The death rate of the individual lesions is shown in Fig. 3.

Ventricular septal defect was the most common individual lesion in this series (99 cases; see appendices and Fig. 3). Although this malformation carries a rather high death rate in infancy, most cases are clinically insignificant. Next came coarctation of the aorta (36 cases), most cases of which may have been of the so-called infantile type with a right-to-left shunt through the ductus arteriosus; the few surviving cases are all of the ordinary type although a persistent ductus was present in two. Third in order came persistent ductus arteriosus ( 35 cases). The seven deaths with this malformation have all occurred in the first month of life. It is, therefore, questionable if all of these really represent deaths from congenital heart disease, but only those are included where the ductus has been unusually wide, sometimes as wide as the aorta, and where the heart had been enlarged. However, in three of the five who died in the first week there was intracranial hæmorrhage and/or asphyxia; this may have been the main cause of death, the large heart being due to respiratory distress.

Fourth in order were atrial septal defects of various kinds with or without anomalous pulmonary venous drainage ( 32 cases). The mortality rate has not been low in these malformations' either. The proportion of cases with anomalous drainage of pulmonary veins is rather high which agrees with our experience elsewhere; the three deaths so far have been instances of total vein transposition.

Next in order are stenosis or atresia of the aortic valve (24 cases), transposition of the great vessels (22 cases), pulmonary stenosis without over-riding aorta (18 cases) and tetralogy of Fallot (15 cases). Aortic atresia and severe aortic stenosis have a poor prognosis, as have mitral atresia 
and stenosis, which are in themselves rare conditions; and transposition of the great vessels is seldom compatible with life beyond the first year. Pulmonary stenosis without over-riding aorta, on the other hand, has a good prognosis in children but this may have been influenced, as in tetralogy of Fallot, by surgical intervention. All cases of tetralogy who have died had pulmonary atresia, and the only death after operation belongs to this group.

The less common lesions like persistent truncus arteriosus, tricuspid atresia, and other more complicated malformations will not be considered in detail.

Sex Ratio. The predominance of girls with persistent ductus is well known and is seen also in

Type of Lesion

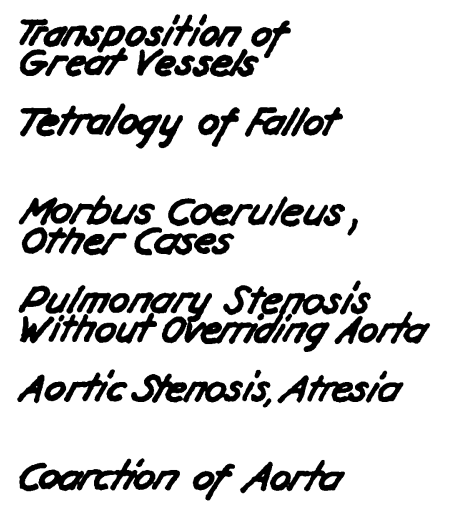

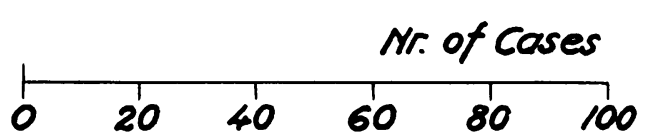
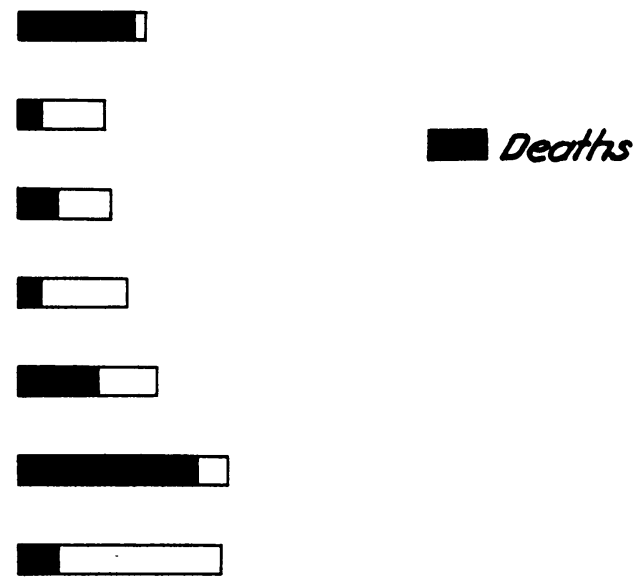

Potent Ductus Arteriosus

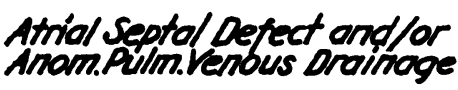

ventricular septol Defect

Miscellaneous Defects

Diagnosis not established

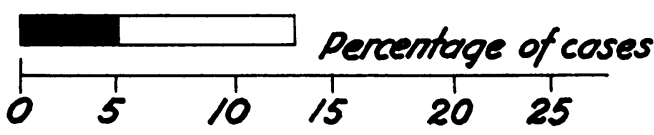

FIG. 3.-Incidence of and mortality rate in the individual types of congenital heart disease.

this series (20 of the 28 surviving cases). All of the seven deaths with this lesion, however, occurred in boys, which may perhaps be an additional argument against the significance of patency in at least some cases. Among the five surviving cases of coarctation of the aorta are four boys; when fatal cases are included there are 21 boys and 15 girls. In transposition of the great vessels the proportion is 15 to 7. The predominance of boys in ventricular septal defect (62 out of 99) was not expected; the difference is probably significant but not statistically so. As regards the other lesions no sex difference has been found.

Age of Child at Recognition of Congenital Heart Disease. The age when cardiac malformation is first recognized is important from a therapeutic point of view since in most operable cases the preschool age is the optimal time for surgery; indeed some of the more severe lesions have to be operated 
on even earlier. For the sake of simplicity only the surviving cases in the present series will be considered in this respect.

Of the 224 cases a murmur or other signs suggestive of congenital heart disease were found in 71 cases in the newborn period. In another 58 the diagnosis was established or at least suspected before the age of one year. In a further 48 the diagnosis was made between one and seven years of age but in no fewer than 47 it was not made until between seven and fourteen years.

In Sweden children begin school at seven years and are all medically examined at this age. Most have attended the children's welfare centres during pre-school age but quite a number may not have been under medical supervision since their first year of life. In the present series the heart lesion was diagnosed for the first time at this school examination in 23 cases, including one case of atrial septal defect, one case of coarctation of the aorta, four cases of persistent ductus and two cases of pulmonary stenosis. Moderate aortic stenosis was found in four cases and insignificant ventricular septal defects in nine. The diagnosis could not be established in the remaining two.

In 24 cases the heart lesion was not detected until a later routine examination was made (including mass radiography). Among these were five cases of atrial septal defect; two cases each of anomalous pulmonary venous drainage (with atrial septal defect), patent ductus, aortic stenosis, idiopathic pulmonary dilatation and isolated dextrocardia; and one case of vascular ring. Four had small ventricular septal defects, and in four no certain diagnosis could be made.

In this series, therefore, 15 cases which now have been operated upon or need to be had escaped notice until the age of seven years or later.

Among the 129 cases where cardiac malformation was recognized or at least suspected before the age of one year are, besides the cyanotic lesions, all known cases of ventricular septal defect with marked left-to-right shunt, all ostium primum defects, and 12 of the 14 cases of simple pulmonary stenosis; while only 8 of the 28 persistent ductus cases and 4 of the 18 with atrial septal defect and/or anomalous pulmonary venous drainage were detected at this early age.

However, among the cases known to have had murmurs already in the newborn period or at least before one year of age, there are also some fifty cases of mild or insignificant ventricular septal defect and other lesions of slight degree. The age when a cardiac malformation is first recognized in a child obviously bears no close relationship to the severity of the lesion.

Incidence of Operable Lesions. To the pædiatrician as well as the surgeon it must be of interest to know the incidence of cardiac malformations amenable to surgery. In the present series of 369 cases 49 have been operated upon so far, and the number of individual lesions and the operative mortality is given below.*

\begin{tabular}{|c|c|c|c|}
\hline Diagnosis & & Number of cases & Deaths \\
\hline Tetralogy of Fallot & . & 10 & 1 \\
\hline Morbus cœruleus, others & .. & .. & \\
\hline Pulmonary stenosis without over-riding aorta & 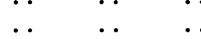 & .. & 0 \\
\hline Coarctation of aorta $\quad . . \quad \ldots \quad \ldots$ & 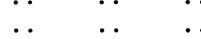 & .. & 0 \\
\hline Persistent ductus arteriosus... & & 21 & 0 \\
\hline Atrial septal defect with anomalous pulmonary & venous drainag & ige & 0 \\
\hline Ostium primum (?) defect ... & .. & .. & 0 \\
\hline
\end{tabular}

In all operations hitherto a closed technique has been used. Some further 15 cases should have surgical intervention in this way but for various reasons it has been delayed. When a pumpoxygenator becomes available, at least 10 cases with ventricular septal defects or ostium primum defects should be considered. In addition some 10 of the 145 deaths (septal defects, pulmonary stenosis) might possibly have been avoided if surgery had been available.

Altogether, the incidence of cases amenable to surgical treatment amounts to about 20 to 25 per cent of the total number of cardiac malformations in this series. This may seem a rather small proportion, but the number of mild or clinically insignificant cases is even greater (about $30 \%$ ).

* The operations were performed by G. Pettersson, M.D., Chief Surgeon, Children's Hospital, Gothenburg. 
In addition, nearly 10 per cent are mongols in whom the benefit of surgery is questionable. However, when such severe malformations as transposition of great vessels, aortic stenosis, and coarctation of aorta (infantile type) are amenable to surgical treatment the percentage of operable cases will be greater.

\section{SUMMARY}

The incidence of congenital heart disease in children born alive in Gothenburg during the years 1941-50 has been investigated. Information was collected from all available sources and practically every child who was known or suspected to have cardiac malformation and was still alive in 1951, when the study was begun, was examined by the present author.

The over-all incidence was 369 cases in 58,105 liveborn children or 6.4 per thousand-about twice as many as in a similar series of MacMahon et al. (1953): the possible explanation for the difference is discussed. The death rate during the time of follow-up (7 to 16 years) was about 40 per cent or 2.5 per thousand live births.

The diagnosis was specified in 87 pet cent of the cases either by autopsy, heart catheterization, or careful clinical examination, which was repeated if necessary, and the figures for the relative incidence of individual lesions are presented. Finally, an estimate is made of the number of cases amenable to surgery at the present time.

I am indebted to Dr. Harry Larsson, Head of the Radiological Department, who carried out the X-ray examinations, and to Mrs. Anna-Greta Glimnert and Miss Dana Samuelsson, who assisted in collecting the material.

\section{REFERENCES}

Abbot, M. E. (1936). Atlas of Congenital Cardiac Disease. American Heart Association, New York. Gardiner, J. H., and Keith, J. D. (1951). Pediatrics, 7, 713.

Gibson, S., and Lewis, K. C. (1952). Amer. J. Dis. Child., 83, 317.

Gyllenswärd, A. (1956). Acta Paediat. (Uppsala), 45, 63

Lundström, R. (1958). Personal communication.

Lyon, R. A., Rauh, L. W., and Stirling, J. W. (1940). J. Pediat., 16, 310.

MacMahon, B., McKeown, T., and Record, R. G. (1953). Brit. Heart J., 15, 121.

McKeown, T., MacMahon, B., and Parsons, C. G. (1953). Brit. Heart J., 15, 273.

Nadas, A. S. (1957). Pediatric Cardiology. W. B. Saunders, Philadelphia and London.

Rauh L. W. (1939). Amer. Heart J., 18, 705.

Record, R. G., and McKeown, T. (1953). Brit. Heart J., 15, 376

Richards, M. R., Merritt, K. K., Samuels, M. H., and Langmann, A. G. (1955a). Pediatrics, $15,169$.

$\longrightarrow,-\longrightarrow,-(1955$ b). Pediatrics, 15, 12.

Robinson, S. J., Aggeler, D. M., and Daniloff, D. T. (1948). J. Pediat., 33, 49.

Rutstein, D. D., Nickerson, R. J., and Heald, F. P. (1952). Amer. J. Dis. Child., 84, 199.

Stuckey, D. (1956). Brit. Heart J., 18, 519.

, Dowd, B., and Walsh, H. (1957). Med. J. Australia, 1, 36.

Taylor, W. (1953). Arch. Dis. Child., $28,52$.

Wood, P. (1950). Brit. med. J., 2, 639.

See Appendix of Cases on pp. 49 and 50. 


\section{APPENDIX A}

Specified Diagnosis in the 145 Fatal Cases

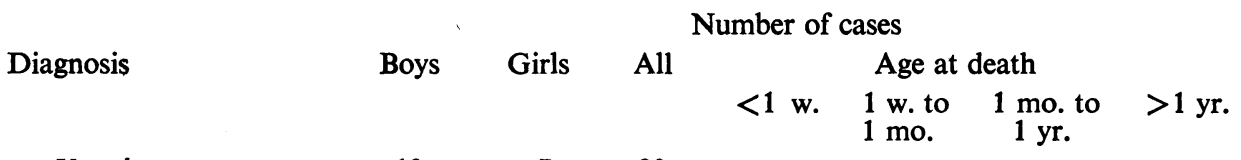

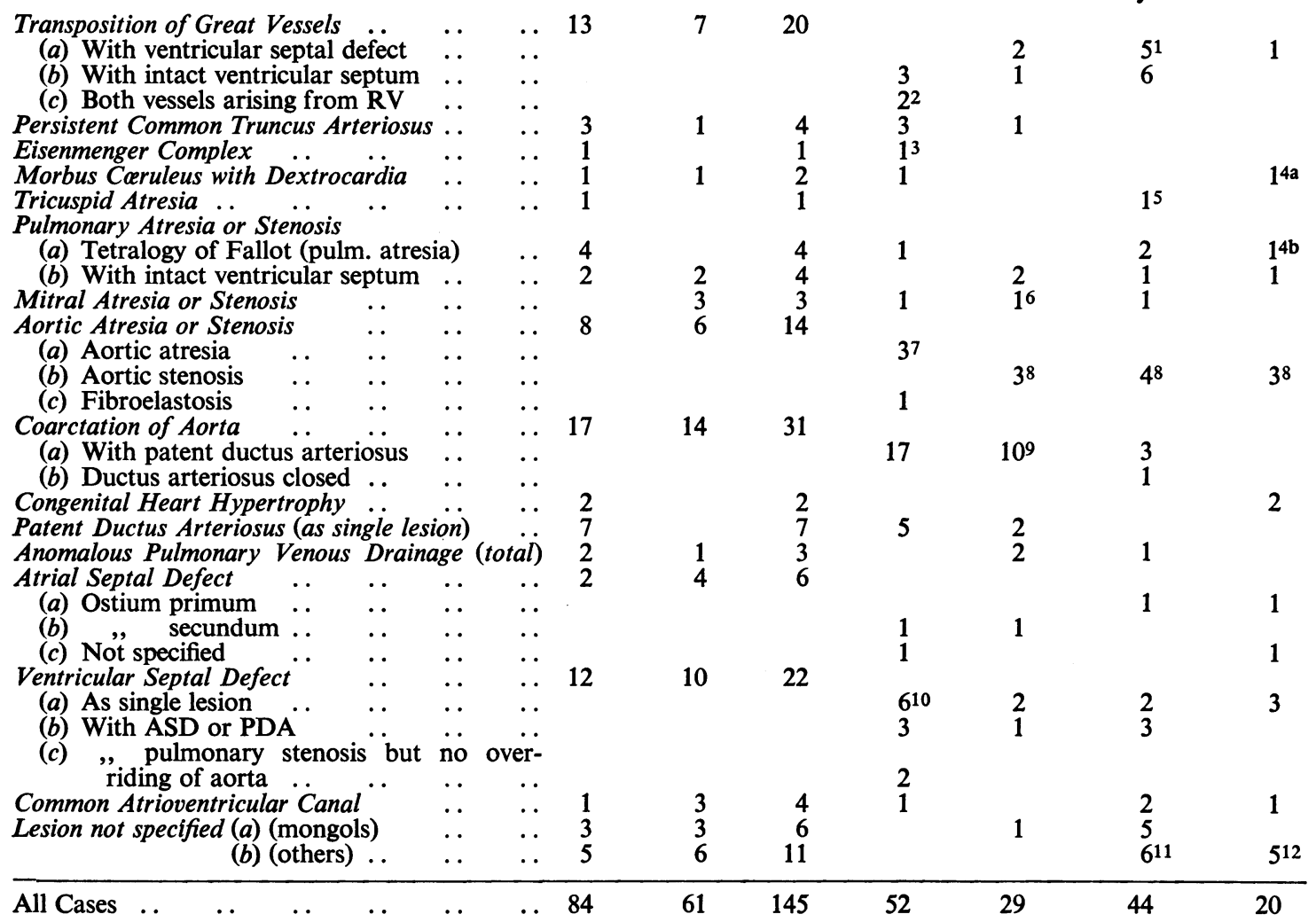

1 Pulmonary atresia in one case.

Notes to Appendix A

\footnotetext{
2 Pulmonary stenosis in one case.

$4 \mathrm{~b}$ Died at operation.

6 Mitral atresia.

8 Myxomatous excrescences in one case.

9 Aortic stenosis in one case.

10 Single ventricle in one case.

11 Morbus coruleus in one case.

12 Morbus cœruleus in two cases.
}

3 Over-riding of aorta; pulmonary stenosis not noted.

4a Died 6 weeks after operation from purulent pericarditis.

5 Transposition of great vessels and pulmonary stenosis (?).

7 Atresia or hypoplasia of aortic arch, and patent ductus with probably fatal shunt direction in two cases. 


\section{APPENDIX B}

Specified Diagnosis in the 224 Cases Alive at the Time of Writing

\section{Diagnosis}

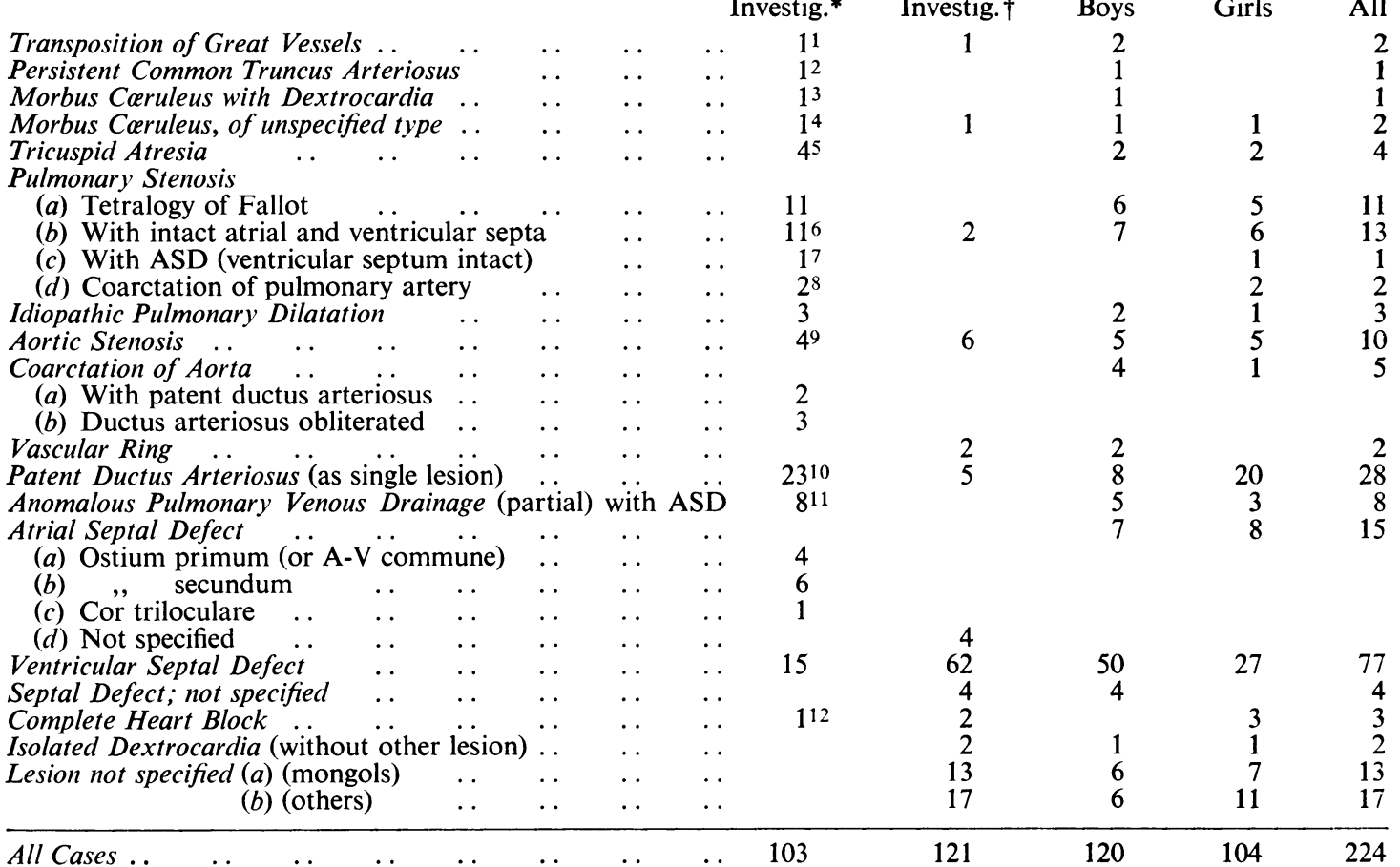

Notes to Appendix $B$

* Includes cardiac catheterization, angiocardiography and/or operation.

† Includes clinical investigation, ECG, phonocardiography, X-ray and sometimes electrokymography.

1 Single ventricle; aorta arising left frontally; probably pulmonary stenosis.

2 Pulmonary infundibular stenosis and valve atresia; over-riding aorta; one great vessel passing from left subclavian artery to the lungs (dilated bronchial artery?)

3 Corrected transposition of great vessels; pulmonary stenosis.

4 Anomalous drainage of systemic veins to left atrium; atrial septal defect; underdeveloped right ventricle; pulmonary hypoplasia.

5 Transposition of great vessels and pulmonary stenosis in one case; under-developed left (?) ventricle and aorta, and reduced pulmonary flow in one case; pulmonary atresia in two cases.

6 Valvular stenosis in ten cases; combined valvular and infundibular in one case.

7 Combined valvular and infundibular stenosis.

8 In both cases at the site of bifurcation.

9 Associated right heart lesion excluded by cardiac catheterization.

10 Left-to-right shunt in all cases.

11 One or two pulmonary veins opening into superior caval vein or (most often) into right atrium.

12 Probably small ventricular septal defect. 